\title{
PRODUÇÃO DA CULTURA DA BETERRABA IRRIGADA COM ÁGUA SALINA
}

\author{
Alexsandro Oliveira da Silva ${ }^{1}$, Antônio Evaldo Klar² ${ }^{2}$ Ênio Farias de França e Silva ${ }^{3}$
}

\section{RESUMO}

A utilização de água de qualidade inferior para a agricultura deve ser realizada com devido cuidado evitando-se o acúmulo excessivo de sais no solo para não prejudicar o desenvolvimento das culturas. Com o objetivo de avaliar o desempenho da cultura da beterraba sob o efeito de águas de qualidade inferior, realizou-se um experimento em casa de vegetação do Departamento de Engenharia Rural da Universidade Estadual Paulista, Botucatu, SP, no período de abril a julho de 2012. Utilizou-se a cultura da beterraba (Beta vulgaris L.) em delineamento experimental inteiramente casualizado, com 6 tratamentos e 5 repetições, totalizando 30 parcelas. Os tratamentos consistiram de soluções de $\mathrm{NaCl}$ de diferentes condutividades elétricas $\left(2,0 ; 3,0 ; 4,0 ; 5,0\right.$ e $\left.6,0 \mathrm{dS} \mathrm{m}^{-1}\right)$ além de um tratamento testemunha correspondente a água sem adição de sal com condutividade elétrica em torno de $0,26 \mathrm{dS} \mathrm{m}^{-1}$. Avaliaram-se as variáveis, produção total, produção comercial, altura das plantas, número de plantas e diâmetro da raiz. A produção da cultura foi prejudicada pelo aumento da salinidade da água de irrigação, caracterizando redução na produção das raízes da cultura. A produção total e comercial apresentaram uma de redução de 8,82 e 12,2\% de acordo com o aumento unitário da salinidade do solo.

Palavras-Chave: Beta vulgaris L., condutividade elétrica, evapotranspiração.

\section{ABSTRACT}

\section{BEET PRODUCTION WITH SALT WATER IRRIGATION}

The use of low quality water for agriculture should be performed with care to avoiding excessive accumulation of salts in the soil so not to harm crop development. In order to evaluate the performance of beets under the influence of low water quality, an experiment was conducted in a greenhouse of the Department of Agricultural Engineering, Universidade Estadual Paulista in Botucatu, Brazil, from April to July 2012. We used the beet (Beta vulgaris L.) in a completely randomized design with 6 treatments and 5 replications, totaling 30 plots. Treatments consisted of $\mathrm{NaCl}$ solutions at different concentrations $\left(2.0,3.0,4.0,5.0\right.$ and $\left.6.0 \mathrm{dS} \mathrm{m}^{-1}\right)$ plus a control treatment corresponding to water with no additional salt and electrical conductivity of roughly $0.26 \mathrm{dS} \mathrm{m}^{-1}$. Variables evaluated were total production, commercial production, plant height, number of plants and root diameter. Production of the beet crop was affected by the increasing salinity of irrigation water, characterized by reduced root production of the beets. Total and commercial production showed reductions of 8.82 and $12.2 \%$ in accordance with the unit increase of salinity.

Keywords: Beta vulgaris L., electrical conductivity, evapotranspiration.

Recebido para publicação em 30/09/2012. Aprovado em 23/04/2013.

1- Engenheiro Agrônomo, Doutorando em Irrigação e Drenagem da FCA/UNESP, Botucatu, SP, alexsandro01@fca.unesp.br

2 - Engenheiro Agrônomo, Prof. Emérito da FCA/UNESP, Botucatu, SP, klar@fca.unesp.br

3 - Engenheiro Agrícola, Prof. Adjunto da UFRPE, Recife, PE, enio.silva@dtr.ufrpe.br 


\section{INTRODUÇÃO}

As águas utilizadas para irrigação normalmente são de origem superficial ou subterrânea, levando-se em conta que em determinadas zonas áridas as características climáticas e a escassez de recursos hídricos limitam a disponibilidade de água, tornando-se necessário o emprego de outras fontes de água disponíveis, como as águas residuárias de procedência urbana (ALMEIDA, 2010) e as águas salobras de origem subterrâneas (SILVA et al., 2011). O aumento da população e a falta de águas superficiais em determinadas áreas forçam a agricultura a procurar fontes de água alternativas como a utilização de águas de qualidade inferior, pois a disponibilidade de águas superficiais em algumas regiões do país servem apenas para consumo humano. Neste contexto, a utilização de águas de qualidade inferior como a de origem salobra deve ser realizada com adequado manejo para evitar o acúmulo excessivo de sais no solo, prejudicando o desenvolvimento das culturas. Segundo Ayers e Westcot (1999), a qualidade da água pode variar de acordo com o tipo e quantidade de sais dissolvidos, causando problemas quando os sais acumulam-se na zona radicular de maneira excessiva, ocasionando perdas na produção.

Apesar do efeito negativo provocado pela salinidade na água de irrigação na agricultura, as diversas culturas usadas para fins agrícolas apresentam respostas diferentes no aspecto produtivo quando são submetidas ao mesmo nível de salinidade. Algumas culturas são mais tolerantes a salinidade que outras e podem absorver água em meio salino com mais facilidade. Por isso são necessários estudos sobre o cultivo das diversas espécies utilizadas para fins agrícolas e suas relações com águas de qualidade inferior. $\mathrm{Na}$ literatura nacional, apesar de haver estudos sobre várias culturas submetidas a águas salinas (SILVA et al., 2011; FIGUEIRÊDO et al., 2009; RESENDE; CORDEIRO, 2007; GERVÁSIO et al., 2000), são poucos os trabalhos envolvendo a cultura da beterraba (Beta vulgaris L.), pois como a mesma apresenta ser semi tolerante à salinidade (AYERS; WESTCOT, 1999; KATERJI et al., 2003; KATERJI et al., 2000), o cultivo é realizado de maneira negligente sem preocupação com a água de irrigação utilizada. Assim, o uso de água de irrigação de má qualidade associados a um manejo inadequado da cultura pode provocar a degradação da área plantada e abandono da terra por parte dos produtores (FERREIRA et al., 2006) reduzindo assim o plantio desta cultura no país.

Portanto, estudos relacionados com localidade de cultivo, manejo e qualidade da água de irrigação devem ser realizados para alcançar uma produção sustentável e sem prejuízos. O Estado de São Paulo se apresenta como um dos maiores produtores de beterraba do Brasil, sendo uma das 15 principais hortaliças em área plantada no Estado (TRANI et al., 1997; TRANI, 2005). Levando-se em conta tal produção, a qualidade da água com que o cultivo é produzido deve ser levado em consideração, além dos demais critérios agronômicos exigidos pela cultura.

O presente trabalho tem como objetivo estudar o efeito de águas salinas usadas para a irrigação no cultivo da beterraba e observar os seus efeitos quanto à produtividade da cultura $\mathrm{e}$ parâmetros de crescimento e sua acumulação no solo durante o ciclo de cultivo.

\section{MATERIAIS E MÉTODOS}

O experimento foi realizado em casa de vegetação no Departamento de Engenharia Rural da Universidade Estadual Paulista no município de Botucatu, SP, no período de abril a julho de 2012. Utilizou-se a cultura da beterraba (cv. Early Wonder) semeadas em vasos de polietileno com capacidade de $14 \mathrm{~L}$ e providos de um sistema de drenagem em sua parte inferior com $3 \mathrm{~cm}$ de brita $\mathrm{n}^{\mathrm{o}} 1$ e manta poliéster. Foram colocados pratos de plásticos em baixo dos vasos para verificação de possível drenagem. O material de solo utilizado foi retirado da camada superficial de 0 a $30 \mathrm{~cm}$ e foi caracterizado como Latossolo VermelhoAmarelo (EMBRAPA 1999), o mesmo foi seco, destorroado e previamente peneirado em peneira de malhas de $4 \mathrm{~mm}$. Foram realizadas análises físicas do solo (Quadro 1) no Departamento de Ciências do solo da UNESP/FCA, sendo classificado como argiloso. 
Quadro 1. Granulometria e parâmetros físicos e hídricos do solo

\begin{tabular}{cccccccc}
\hline & \multicolumn{5}{c}{ Parâmetros físico-hídricos } \\
\hline $\begin{array}{c}\text { Areia } \\
\left(\mathrm{g} \mathrm{kg}^{-1}\right)\end{array}$ & $\begin{array}{c}\text { Silte } \\
\left(\mathrm{g} \mathrm{kg}^{-1}\right)\end{array}$ & $\begin{array}{c}\text { Argila } \\
\left(\mathrm{g} \mathrm{kg}^{-1}\right)\end{array}$ & $\begin{array}{c}\mathrm{dg} \\
\left(\mathrm{g} \mathrm{cm}^{-3}\right)\end{array}$ & $\begin{array}{c}\mathrm{ds} \\
\left(\mathrm{g} \mathrm{cm}^{-3}\right)\end{array}$ & $\begin{array}{c}\mathrm{P} \\
(\%)\end{array}$ & $\begin{array}{c}\mathrm{Cc} \\
\left(\mathrm{g} \mathrm{g}^{-1}\right)\end{array}$ & $\begin{array}{c}\text { PMP } \\
\left(\mathrm{g} \mathrm{g}^{-1}\right)\end{array}$ \\
\hline 395,5 & 138,1 & 466,4 & 2,77 & 1,28 & 53,9 & 0,27 & 0,17 \\
\hline
\end{tabular}

dg- densidade das partículas; ds - densidade do solo; P - porosidade total; Cc - umidade na capacidade de campo; PMP - umidade no ponto de murcha permanente

Quadro 2. Características químicas do solo

\begin{tabular}{ccccccccccc}
\hline $\mathrm{pH} \mathrm{CaCl}_{2}$ & $\begin{array}{c}\mathrm{CE} \\
\mathrm{dS} \mathrm{m}^{-1}\end{array}$ & $\begin{array}{c}\mathrm{M} . \mathrm{O} \\
\mathrm{g} \mathrm{dm}^{-3}\end{array}$ & $\begin{array}{c}\mathrm{P} \\
\mathrm{mg} \mathrm{dm}^{-3}\end{array}$ & $\mathrm{~K}$ & $\mathrm{Ca}$ & $\mathrm{Mg}$ & $\begin{array}{c}\mathrm{H}+\mathrm{Al} \\
\mathrm{mmol}_{\mathrm{c}} \mathrm{dm}^{-3}\end{array}$ & $\mathrm{SB}$ & $\mathrm{CTC}$ & $\begin{array}{c}\mathrm{V} \\
(\%)\end{array}$ \\
\hline 5,1 & 0,32 & 11 & 6 & 0,6 & 22 & 7 & 26 & 29 & 55 & 53 \\
\hline
\end{tabular}

$\mathrm{M} . \mathrm{O}=$ máteria orgânica; $\mathrm{P}$ = fósforo; $\mathrm{K}=$ potássio; $\mathrm{Ca}=$ cálcio; $\mathrm{Mg}=$ magnésio; $\mathrm{H}+\mathrm{Al}=$ acidez potencial; $\mathrm{SB}=\mathrm{sOma}$ de bases; $\mathrm{CTC}=$ complexo de troca catiônica; $\mathrm{V}(\%)=$ saturação por bases

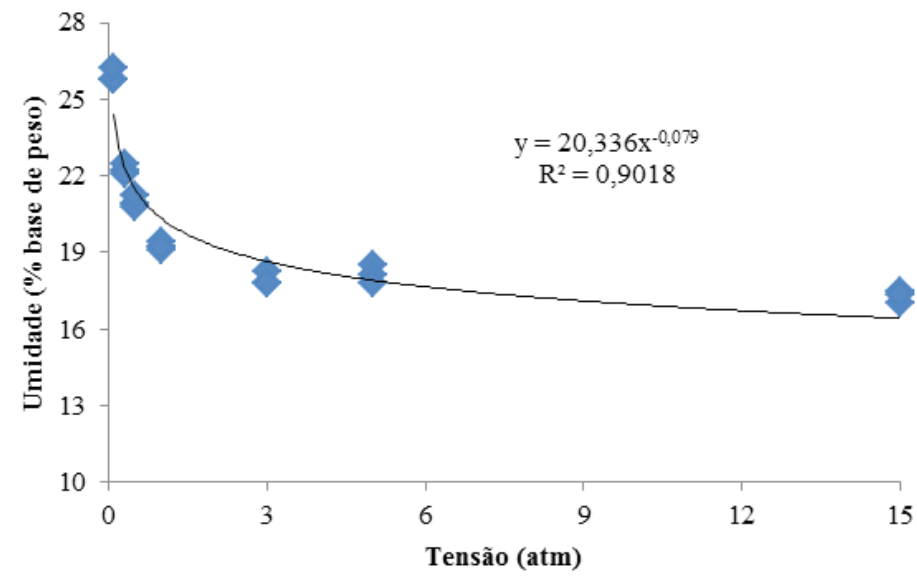

Figura 1. Curva de retenção de água no solo utilizada para o manejo da irrigação.

Com base nas análises químicas realizadas no solo (Quadro 2), procedeu-se à correção da acidez, mediante a aplicação de $\mathrm{CaCO}_{3}$ (elevando a saturação das bases a $80 \%$ ) e adubação conforme recomendações de Trani et al. (1998).

$\mathrm{O}$ delineamento experimental foi o inteiramente casualizado, com 6 tratamentos e 5 repetições, totalizando 30 parcelas (1 planta por parcela). Os tratamentos consistiram de soluções de $\mathrm{NaCl}$ de diferentes condutividades elétricas $(2,0 ; 3,0$; 4,$0 ; 5,0$ e $6,0 \mathrm{dS} \mathrm{m}^{-1}$ ) além de um tratamento testemunha correspondente a água sem adição de sal com condutividade elétrica em torno de $0,26 \mathrm{dS}$ $\mathrm{m}^{-1}$. Determinou-se em laboratório a variação da condutividade elétrica de soluções contendo diferentes concentrações de $\mathrm{NaCl}$. Os dados foram submetidos à análise de regressão, obtendo-se a equação:

$\mathrm{C}_{\mathrm{NaCl}}=0,6653 \cdot \mathrm{CE}_{\mathrm{sol}}-0,3785$ em que

$\mathrm{C}_{\mathrm{NaCl}}=$ concentração de $\mathrm{NaCl}\left(\mathrm{g} \mathrm{L}^{-1}\right) ;$ e,

$\mathrm{CE}_{\text {sol }}=$ condutividade elétrica da solução $\left(\mathrm{dS} \mathrm{m}^{-1}\right)$.

Esta equação foi utilizada para o preparo das soluções, as quais foram acondicionadas em recipientes devidamente fechados e renovadas semanalmente. $\mathrm{O}$ início do experimento caracterizou-se por elevar a umidade do solo à capacidade de container, saturando-se os vasos com água sem sal e vedando-os com plástico, forçando a perda apenas por drenagem, retirando-se os plásticos após 2 dias. Em seguida foram colocadas duas mudas de beterraba por vaso e após 10 dias após transplantio (DAT) foram deixadas apenas uma planta por vaso (com melhor desenvolvimento vegetativo). 
Realizou-se o manejo da irrigação a partir da leitura da tensão média (realizada por tensímetro digital) em cada tratamento estudado, a irrigação era realizada quando a tensão média de cada tratamento atingia $30 \mathrm{kPa}$, as medidas de tensão da água no solo foram feitas através de tensiômetros de punção, instalados em cada parcela. Observadas as tensões de cada tratamento, calcularam-se as umidades correspondentes, a partir da curva de retenção de água no solo (Figura 1), obtida através da placa de pressão, conforme descrito por Libardi (2005).

De posse das umidades encontradas em cada solo e daquela correspondente à capacidade de container e ainda, considerando-se o volume de solo presente no vaso, calculou-se o volume de reposição (HASSANLI et al., 2010), conforme equação 2. Para aplicação da água de irrigação nos vasos (feito manualmente com auxílio de becker graduado), transformou-se a lâmina líquida de irrigação (LLI) em volume (L por vaso) multiplicando-se LLI pela área do vaso $\left(0,062 \mathrm{~m}^{2}\right)$.

$L L I=\left(\frac{\theta_{c c}-\theta_{\text {atual }}}{10}\right) \cdot d s \cdot Z$

em que

LLI = Lâmina líquida de irrigação (mm);

$\theta_{\mathrm{cc}}=$ Umidade na capacidade de container $(\% \mathrm{em}$ peso);

$\theta_{\text {atual }}=$ Umidade atual ( $\%$ em peso);

ds $=$ densidade do solo $\left(\mathrm{g} \mathrm{cm}^{-3}\right)$; e,

$\mathrm{Z}=$ profundidade do sistema radicular $(\mathrm{cm})$;

Estimou-se semanalmente como feito por Gervásio et al. (2000) a salinidade do solo, expressa pela condutividade elétrica do extrato saturado ao longo do ciclo da cultura para fins de rendimento da cultura no final do ciclo, obtida através da equação 3:

CEes $=\frac{V a \cdot C E a}{P S . U S}$

em que

CEes $=$ Condutividade elétrica do extrato saturado estimada $\left(\mathrm{dS} \mathrm{m}^{-1}\right)$;

$\mathrm{Va}=$ volume de água aplicado (L);
$\mathrm{CEa}=$ Condutividade elétrica da água de irrigação $\left(\mathrm{dS} \mathrm{m} \mathrm{m}^{-1}\right)$;

Ps = massa do solo $(\mathrm{kg})$; e,

Us $=$ Umidade de saturação $\left(\mathrm{kg} \mathrm{kg}^{-1}\right)$.

A evapotranspiração da cultura (ETc) foi determinada a partir do balanço hídrico feito no vaso com auxílio dos tensiômetros instalados. Os componentes do balanço hídrico (LIBARDI, 2005) podem ser descritos conforme equação 4 :

$$
\Delta A r m=P+I \pm R+A C-D P-E T c
$$

em que

$\Delta$ Arm $=$ variação de armazenamento do solo $(\mathrm{mm}) ;$ $\mathrm{P}=$ precipitação $(\mathrm{mm})$;

$\mathrm{I}=$ irrigação $(\mathrm{mm})$;

$\mathrm{R}=$ escoamento superficial ou run off $(\mathrm{mm})$;

$\mathrm{AC}=\mathrm{a}$ ascensão capilar $(\mathrm{mm})$;

$\mathrm{DP}=$ é a drenagem profunda $(\mathrm{mm}) ; \mathrm{e}$,

$\mathrm{ETc}=$ é a evapotranspiração real da cultura (mm).

Nas condições em que foi realizado o experimento, os termos $\Delta$ Arm, $\mathrm{P}, \mathrm{R}, \mathrm{AC}$ e $\mathrm{DP}$ foram considerados nulos, por se tratar de culturas cultivadas em vasos, com irrigação frequente e sob ambiente protegido. Rearranjando os termos da equação 4, tem-se:

$\mathrm{ETc}=\mathrm{I}$

Nestes termos, assume-se que o valor de ETc entre dois eventos de irrigação é igual à quantidade de água aplicada no solo no tratamento em questão, considerando- se ainda que a umidade foi uniforme em todo o perfil da profundidade de instalação dos tensiômetros.

Ao final do experimento (60 dias após o transplantio), avaliaram-se as seguintes variáveis: produção total (peso da parte aérea + raiz) e produção comercial (peso da raiz), pesadas imediatamente após a colheita com auxílio de balança comercial, altura das plantas, medidas utilizando-se uma de fita métrica tendo como base a superfície do solo e a folha de maior desenvolvimento, número de plantas e diâmetro da raiz, medido com auxílio de um paquímetro digital e a evapotranspiração da cultura.

\section{REVENG}


As variáveis foram submetidas ao teste de variância e posteriormente a análise de regressão com auxílio do software $\mathrm{R}$ versão 2.8.0 ( $\mathrm{R}$ Development Core Team, 2008). Na análise de regressão foram testados os modelos linear e polinomial de $2^{\circ}$ grau. As equações de regressão foram escolhidas com base na significância dos coeficientes de regressão, a 0,01 e 0,05 de probabilidade, pelo teste $\mathrm{F}$ e com base no maior valor do coeficiente de determinação $\left(\mathrm{R}^{2}\right)$.

\section{RESULTADOS E DISCUSSÃO}

Os níveis de salinidade afetaram significativamente os resultados da produção total e comercial além do diâmetro da raiz, altura e o consumo hídrico das plantas (Quadro 3). Ressaltase que o desdobramento dos efeitos dos tratamentos estudados através da análise de regressão, revelou efeito linear sobre as variáveis. Hassanli et al. (2010) em estudos sobre a influência de métodos de irrigação e a qualidade da água na produção de beterraba açucareira, observaram efeito significativo da salinidade da água na produção de raízes da cultura. Em estudos como o de Silva (2012) e Katerji et al. (2000), atribui-se a redução nos valores da produção e no consumo hídrico das plantas ao potencial osmótico acrescido na solução do solo devido ao excesso de sais presentes, dificultando a absorção de água por parte da planta, fazendo com que a mesma precise de maior esforço energético para a absorção de água e nutrientes.

Observou-se que o consumo de água pelas plantas, durante o ciclo de produção, diminuiu com níveis crescentes de salinidade da água de irrigação, evidenciando um déficit de evapotranspiração de $27 \%$ para o tratamento com água com $6 \mathrm{dS} \mathrm{m}^{-1}$ de condutividade elétrica (Figura 2). O mesmo aspecto foi observado por Gervásio et al. (2000) em cultivo de alface submetida a águas com diferentes salinidades. Katerji et al. (2000), em estudos sobre a tolerância de culturas à salinidade, observaram que a beterraba açucareira apresentou redução significativa no consumo hídrico quando submetida a água de condutividade elétricas de $6,3 \mathrm{dS} \mathrm{m}^{-1}$.

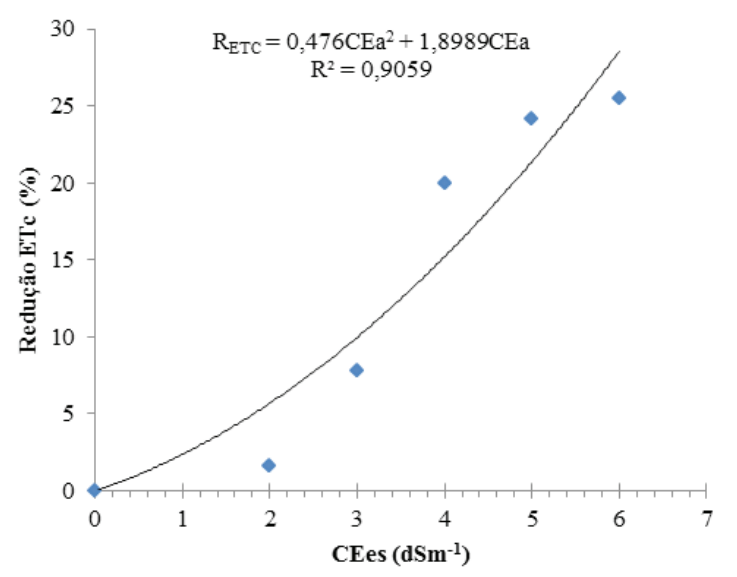

Figura 2. Redução na evapotranspiração em função da salinidade da água de irrigação durante o ciclo de produção da beterraba.

Adotando-se a equação estimada na Figura 2, avaliaram-se as variáveis vegetativas em função da redução da evapotranspiração. Verificou-se pela Figura 3, uma redução média de 40, 25,9 e $26,9 \%$ para as variáveis; produção total (Figura $3 \mathrm{~A}$ ), produção comercial (Figura 3B) e diâmetro

Quadro 3. Resumo da análise de variância para produção total (PT), produção comercial (PC), altura das plantas (ALT), diâmetro da raiz (DR), número de folhas (NF) e evapotranspiração (ETc)

\begin{tabular}{ccccccc}
\hline \multicolumn{7}{c}{ Quadrados médios } \\
\hline Fonte variação & PT & PC & ALT & DR & NF & ETc \\
\hline Bloco & $169,58^{\text {ns }}$ & $476,22^{\text {ns }}$ & $9,53^{\text {ns }}$ & $132,3^{\text {ns }}$ & $23,2^{\text {ns }}$ & $12,2^{\text {ns }}$ \\
Salinidade da água & $4111,3^{* *}$ & $3641,33^{* *}$ & $172,52^{* *}$ & $536,6^{* *}$ & $2,08^{\text {ns }}$ & $503,2^{* *}$ \\
Resíduo & 182,58 & 226,75 & 21,79 & 25,04 & 5,59 & 14,1 \\
\hline CV (\%) & 12,95 & 16,98 & 18,10 & 10,54 & 12,40 & 8,2 \\
\hline
\end{tabular}

ns: não significativo, ${ }^{* *}$ : significativo a probabilidade de $5 \%$ pelo teste $\mathrm{F}$. 

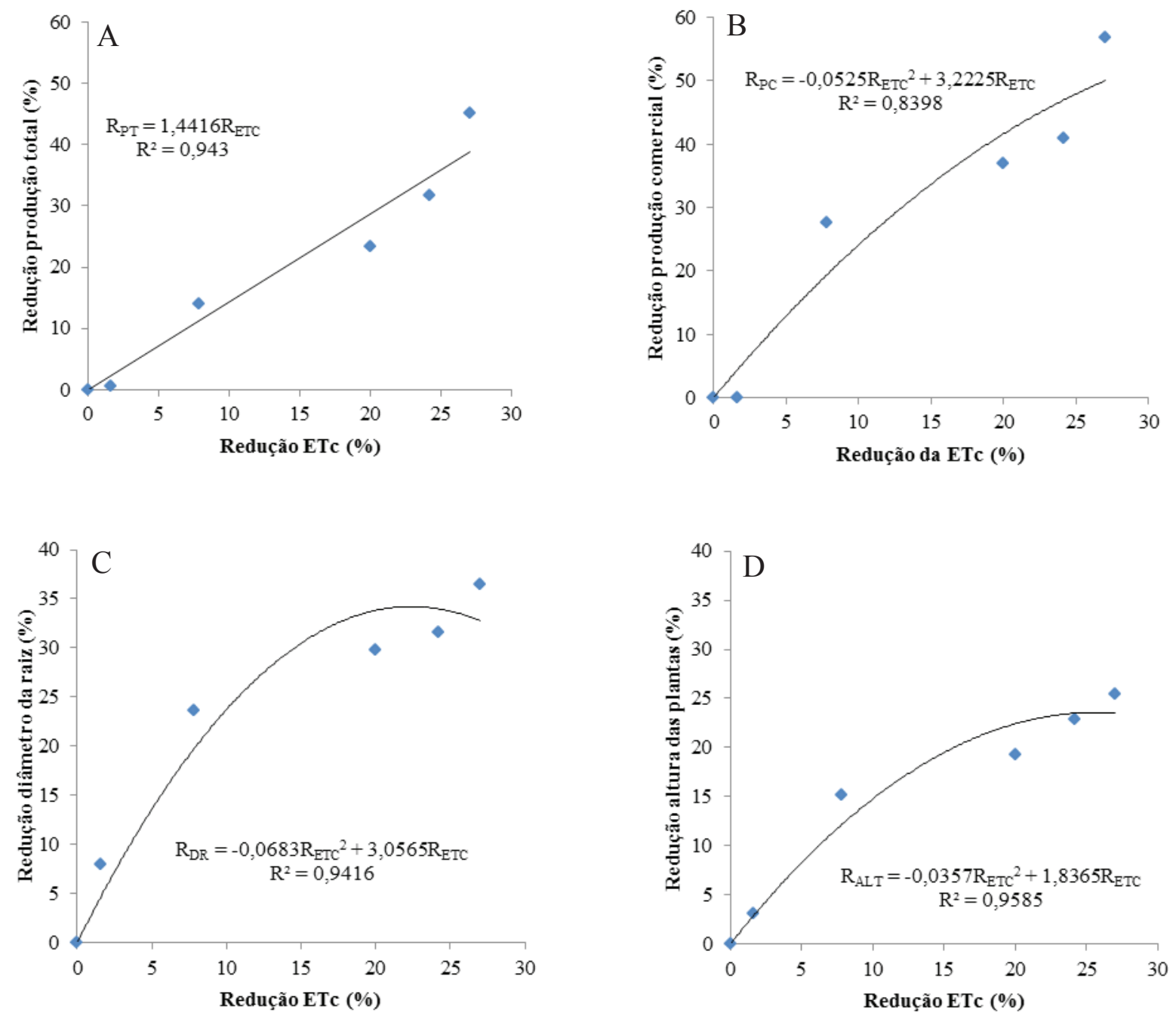

Figura 3. Respostas das variáveis vegetativas em função da redução de evapotranspiração da cultura da beterraba.

da raiz (Figura 3C), respectivamente. Observase uma redução nos parâmetros vegetativos semelhantes aos encontrados para a redução da evapotranspiração, exceto para a produção total que ficou acima da redução média dos demais parâmetros. A altura das plantas (Figura 3D) apresentou uma redução expressiva a partir da salinidade da água no nível de $3 \mathrm{dS} \mathrm{m} \mathrm{m}^{-1}$, representada por $15 \%$ da redução da ETc, havendo aumento progressivo desta redução até os $25 \%$ no tratamento mais crítico.

Melo et al. (2011) trabalhando com a cultura do meloeiro, observaram a redução na evapotranspiração de acordo com o aumento da salinidade da água de irrigação, havendo em torno de $15 \%$ de perda na produtividade da cultura. Almodares e Sharif (2007) avaliando o efeito da qualidade da água de irrigação na biomassa de cultivares de beterraba, observaram uma redução no rendimento da cultura de acordo com o aumento da condutividade elétrica na água de irrigação, obtendo-se valores de $64435 \mathrm{~kg}$ $\mathrm{ha}^{-1}$ para águas de condutividade elétrica (CE) de $2 \mathrm{dS} \mathrm{m}^{-1}$ e $48359 \mathrm{~kg} \mathrm{ha}^{-1}$ para águas com 11 $\mathrm{dS} \mathrm{m} \mathrm{m}^{-1}$ de CE, apresentando uma redução de $25 \%$ dos valor total de produção. Por isto, deve-se observar o rendimento da cultura nas diferentes fases e aspectos relacionados à cultura quanto a tolerância aos sais.

Estimou-se a condutividade elétrica do extrato de saturação (CEes) ao longo do ciclo da cultura, sendo que ao final do mesmo observou-se que os valores oscilaram entre 0,66 e 12,2 $\mathrm{dS} \mathrm{m}^{-1}$ para os níveis de salinidade da água de irrigação de 0,26 e $6 \mathrm{dS} \mathrm{m}^{-1}$, respectivamente (Figura 4). Os valores estimados para a CEes no final do ciclo foram em média 4 vezes maior do que o valor inicial da condutividade elétrica no solo, o que demonstra 
problemas no solo devido a evolução da salinidade para o cultivo submetido com águas de qualidade inferior. Tal acúmulo de sais no solo provoca a redução dos fatores produtivos da planta, além de afetar o desenvolvimento das raízes da cultura como afirma Chen e Jiang (2010), em estudos sobre o ajustamento osmótico da cultura da beterraba.

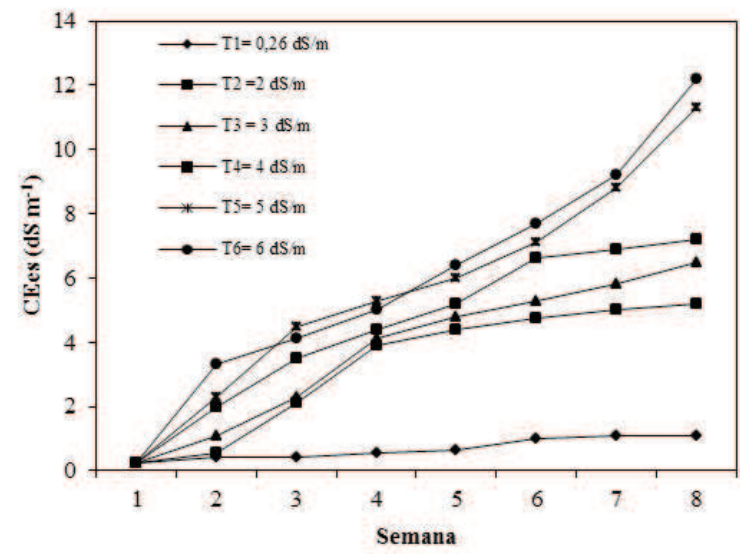

Figura 4. Estimativa da condutividade elétrica do extrato de saturado durante o ciclo produtivo da beterraba, para diferentes níveis de salinidade da água de irrigação.

Verifica-se, na Figura 5, que o rendimento relativo da produção total foi inferior ao da produção comercial devido à parte aérea da planta ter sido mais sensível a salinidade da água de irrigação com relação à produção da raiz, ou seja, para um mesmo valor de condutividade elétrica do extrato saturado, o rendimento em termos comerciais foi maior que a produção total da planta. Tais resultados foram semelhantes aos observados por Resende e Cordeiro (2007), em estudos com a cultura da beterraba submetida a águas de qualidade inferior no semiárido do submédio do São Francisco. Os resultados deste estudo foram diferentes dos apresentados Mass e Hoffman (1977), porém deve-se ressaltar que as condições climáticas, o tipo de solo, o sistema de irrigação, além da espécie utilizada, podem contribuir de maneira significativa para diferenças no rendimento da cultura. Silva (2012), em estudos sobre o excesso de sais fertilizantes, provocados pela fertirrigação na cultura da beterraba de mesa, também encontraram valores inferiores aos apresentados por Mass e Hoffman (1977), ressaltando assim a menor tolerância da beterraba de mesa quando comparada com a beterraba açucareira.

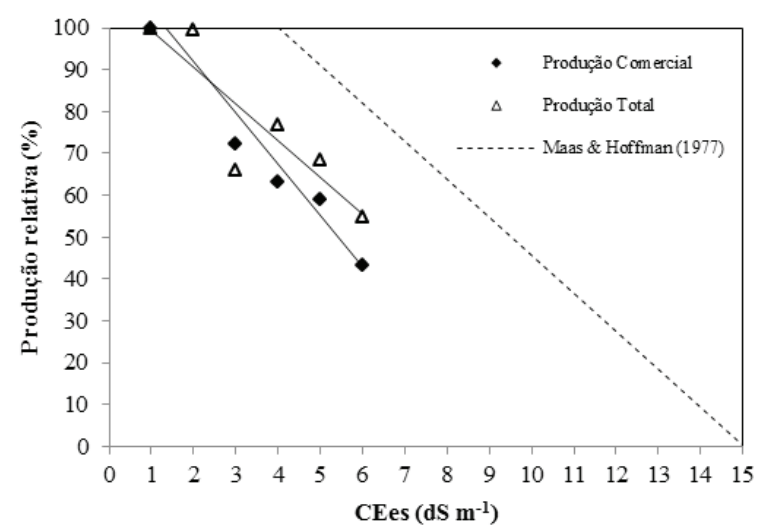

Figura 5. Produção total e comercial da beterraba em função da condutividade elétrica do extrato saturado.

No Quadro 4 mostram-se as equações de regressão para as produções total e comercial em função da salinidade do solo, verifica-se uma redução para a produção total e comercial devido ao aumento da condutividade elétrica do solo. Tais resultados se aproximam do apresentado por Resende e Cordeiro (2007), em que os autores estudaram os efeitos da salinidade na água da irrigação na beterraba de mesa no semiárido nordestino, que apresentou redução de $44 \%$ na produção da cultura submetida a água com CE de 4,0 dS m$~^{-1}$. Porém, a redução obtida neste trabalho diferem da apresentada por Maas e Hoffman (1977), que obtiveram queda de $25 \%$ na produção a partir da condutividade elétrica de $6,6 \mathrm{dS} \mathrm{m}^{-1}$. No presente estudo a salinidade do solo afetou o desenvolvimento da beterraba a partir da condutividade elétrica de $4 \mathrm{dS} \mathrm{m}^{-1}$, com redução de $8,82 \mathrm{~g}$ para a produção total e $12,238 \mathrm{~g}$ para a produção comercial a cada aumento unitário da condutividade elétrica do solo. Katerji et al. (2000), avaliando diferentes classificações de tolerância da cultura da beterraba açucareira a salinidade, observaram que não houve redução drástica da cultura a águas de qualidade inferiores com $\mathrm{CE}$ de $7,0 \mathrm{dS} \mathrm{m}^{-1}$. 
Quadro 4. Equações de regressão para as produções relativa (total e comercial) da beterraba em função da condutividade elétrica do extrato saturado, ao final do ciclo produtivo

\begin{tabular}{lcc}
\hline Produção & \multicolumn{1}{c}{ Equação } & $\mathrm{R}^{2}$ \\
\hline Total & $\mathrm{PT}=-8,8237^{* *}$ CEes $+108,44^{* *}$ & 0,79 \\
Comercial & $\mathrm{PC}=-12,238^{* *}$ CEes $+116,46^{* *}$ & 0,91 \\
\hline
\end{tabular}

** significativo a 5\% de probabilidade; CEes: condutividade elétrica do extrato de saturação

\section{CONCLUSÕES}

- A produção da cultura da beterraba foi prejudicada pelo aumento da salinidade da água de irrigação, caracterizando redução na produção das raízes da cultura.

- A salinidade afetou mais a produção total que a comercial até a salinidade de $2,3 \mathrm{dS}$ $\mathrm{m}^{-1}$, a partir de então a produção comercial foi afetada de maneira mais significativa, possivelmente devido ao contato da raiz com solos de elevada salinidade.

- A produção total e comercial apresentaram redução de 8,82 e 12,2\% de acordo com o aumento unitário da salinidade do solo.

\section{REFERÊNCIAS BIBLIOGRAFICAS}

ALMEIDA, O.A. de. Qualidade da água de irrigação. Cruz das Almas: Embrapa mandioca e fruticultura, 2010. 234p.

ALMODARES, A.; SHARIF, M.E. Effects of irrigation water qualities on biomass and sugar contents of sugar beet and sweet sorghum cultivars.

Journal of Environmental Biology, Amsterdam, v.28, n.2, p.213-218, 2007.

AYERS, R.S.; WESTCOT, D.W. (trad.) A qualidade da água na agricultura. Campina Grande: UFPB, 1999. 218p. (Estudos FAO. Irrigação e Drenagem, 29).

CHEN, H.; JIANG, J.G.Osmotic adjustment and plant adaptation to environmental changes related to drought and salinity. Environmental Reviews, Ottawa, v.18, p.309-319, 2010.

EMBRAPA. Empresa Brasileira de Pesquisa Agropecuária. Centro Nacional de Pesquisas de Solos. Sistema Brasileiro de classificação de solos. Rio de Janeiro: Embrapa Solos. 1999. 412p.

FIGUEIRÊDO, V.B.; MEDEIROS, J.F.; ZOCOLER, J.L.; SOBRINHO, J.E. Evapotranspiração da cultura da melancia irrigada com água de diferentes salinidades. Engenharia Agrícola, Jaboticabal, v.29, n.2, p.231-240, 2009.

FERREIRA, P.A.; MOURA, R.F.; SANTOS, D.B. dos; FONTES, P.C.R.; MELO, R.F. Efeitos da lixiviação e salinidade da água sobre um solo salinizado cultivado com beterraba. Revista Brasileira de Engenharia Agrícola e Ambiental, Campina Grande, v.10, n.3, p.570-578, 2006.

GERVÁSIO, E.S.; CARVALHO, J.A.; SANTANA, M.J. Efeito da salinidade da água de irrigação na produção da alface americana. Revista Brasileira de Engenharia Agrícola e Ambiental, Campina Grande, v.4, n.1, p.125-128, 2000.

HASSANLI, A.M.; AHMADIRAD, S.; BEECHAM, $S$. Evaluation of the influence of irrigation methods and water quality on sugar beet yield and water use efficiency. Agricultural Water Management, Amsterdam, v.97, p.357-362, 2010.

KATERJI, N.; HOORN, J.W.; HAMDY, A.; MASTRORILLI, M. Salinity effect on crop development and yield, analysis of salt tolerance according to several classification methods. Agricultural Water Management, Amsterdam, v.62, p.37-66, 2003.

KATERJI， N.; HOORN， J.N.; HAMDY，A.; MASTRORILLI, M. Salt tolerance classification of crops according to soil salinity and to water stress day index. Agricultural Water Management, Amsterdam, v.43, p.99-109, 2000.

LIBARDI, P.L. Dinâmica da água no solo. São Paulo: EdUSP, 2005, 497p. 
MAAS, E.V.; HOFFMAN, G.H. Crop salt tolerance- Current assessment. Journal of the Irrigation and Drainage Division, American Society of Civil Engineers, Reston, v.103, p.115134, 1977.

MELO, T.K.; MEDEIROS, J.F.; SOBRINHO, J.E.; FIGUEIREDO, V.B.; PEREIRA, V.C.; CAMPOS, M.S. Evapotranspiração e produção do melão Gália irrigado com água de diferentes salinidades e adubação nitrogenada. Revista Brasileira de Engenharia Agrícola e Ambiental, Campina Grande, v.15, n.12, p.1235-1242, 2011.

R Development Core Team. R: A language and environment for statistical computing: reference index version 2.8.0. Vienna Foundation for Statistical Computing, 2008. Disponível em: $<$ http://www.r-project.org.> 11 Jan. 2008

SILVA, A.O. Fertirrigação e controle da salinidade em cultivo de beterraba em ambiente protegido. 2012. 136f. Dissertação (Mestrado em Irrigação e Drenagem) - Universidade Estadual Paulista, Botucatu, 2012.

SILVA, A.O.; SILVA, D.J.R.; SOARES, T.M.; SILVA, E.F.F.; SANTOS, A.N.; ROLIM, M.M. Produção de rúcula em sistema hidropônico NFT utilizando água salina do semiarido-PE e rejeito de dessalinizador. Revista Brasileira de Ciências Agrárias, Recife, v.6, n.1, p.147-155, 2011.

RESENDE, G.M.; CORDEIRO, G.G. Uso da água salina e condicionador de solo na produtividade de beterraba e cenoura no Semi-Árido do submédio São Francisco. Petrolina: Embrapa Semi-Árido, 2007, 4p. (Comunicado técnico $\left.\mathrm{n}^{\circ} 128\right)$.

TRANI, P.E.; CANTARELLA, H.; TIVELLI, S.W. Produtividade de beterraba em função de doses de sulfato de amônio em cobertura. Horticultura Brasileira, Brasília, v.23, n.3, 2005.

TRANI, P.E.; PASSOS, F.A.; TAVARES, M.; AZEVEDO FILHO, J. A. Hortaliças. In: VAN RAIJ, B.; CANTARELLA, H.; QUAGGIO, J.A.; FURLANI, A.M.C. Recomendações de adubação e calagem para o Estado de São Paulo,

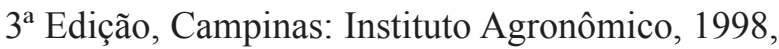
285p. (Boletim técnico, 100).

TRANI, P.E.; GROPPO, G.A.; SILVA, M.C.P.; MINAMI, K; BURKE, T.J. Diagnóstico sobre a produção de hortaliças no estado de São Paulo. Horticultura Brasileira, Brasília, v.15, n.1, p.1924, 1997. 